\title{
Planetary Defense Preparedness: \\ Identifying the Potential for Post-asteroid Impact Time Delayed and Geographically Displaced Hazards
}

Corresponding Author: T. N. Titus (U.S. Geological Survey Astrogeology Science Center; ttitus@usgs.gov; 928-556-7201)

Co-authors: D. Robertson (NASA Ames Research Center), J.B. Sankey (U.S. Geological Survey, Southwest Geological Science Center)

Acknowledgements: A.J. Oliphant and I.P. Aneece provided valuable insights that greatly improved the paper.

Signatories:

A.J. Oliphant, U.S Geological Survey, Western Geography Science Center

I.P. Aneece, U.S. Geological Survey, Western Geography Science Center

Mark Sykes, Planetary Space Institute

William Hartmann, Planetary Science Institute

Lorien Wheeler, NASA Ames Research Center

Peter Jenniskens, SETI, NASA Ames Research Center

Michael Aftosmis, NASA Ames Research Center

Clemens Rumpf, NASA Ames Research Center 
Introduction: A considerable amount of effort has been done to quantify the effects of an asteroid impact on Earth, including processes such as air blast with overpressure shock and thermal radiation, crater formation and ejecta deposition, seismic shaking, and tsunamis (e.g. Hills \& Goda, 1993; Collins et al., 2005, Rumpf et al., 2017; Robertson \& Mathias 2019a, b). These first-order effects are typically localized in time and diminish with increased distance from the impact (or air burst) location.

However, delayed downstream and downwind effects will propagate, and disturb areas not immediately affected by the initial impact. Downstream effects could occur months after the impact as sediment and debris are washed into reservoirs, potentially changing water quality for populations not originally affected by the impact event. These effects are analogous to those following a major wildfire. Downwind effects could deposit dust and debris hundreds or thousands of kilometers downwind, reducing insolation and ultimately settling out over large areas which could include cropland. These effects are analogous to those following a pyroclastic volcanic eruption. Ground and air transportation may be significantly disrupted. Depending on the time of year of the impact, significant damage could occur to croplands.

For small asteroid impacts, these delayed effects are expected to be negligible beyond the initial damage zone. However, there are likely a class of impacts (e.g. impactor size and composition, impact location and time of year) where failure to consider these effects could complicate postimpact relief and recovery efforts. For example, evacuation of the population within the initial damage zone from an impact to a city downstream could exacerbate water quality issues and water usage months later. A mid-sized impact in western Nebraska might have minimal civil defense requirements for evacuation (due to the low population density) but the downwind effects could potentially disrupt the agriculture and the economic health of the American Midwest, threatening global food security. Understanding the relevance and associated costs of these time-delayed and geographically displaced effects is important to ensure successful civil defense and recovery planning. The cost to launch a mission to intercept an asteroid is well known, but the costs of an impact in rural areas may be seriously underestimated if long-term effects are not considered.

National Action Plan: In 2018, the Whitehouse released a National Near-Earth Object (NEO) Preparedness Strategy and Action Plan (hereafter called the Action Plan) providing a framework for both agency and interagency efforts. Within the Action Plan, action item 5.8 specifically identifies the incorporation of NEO impacts into all-hazards response and recovery plans. The consideration of time-delayed effects should also be considered as part of the all-hazards response and recovery plans. In addition, action item 2.2 recommends we "ascertain what information each participating organization requires on what timeframe, identify gaps, and develop recommendations for modeling improvements." This white paper addresses the need for models to anticipate and predict delayed effects on regional areas. Many of these effects are likely delayed by several months and could complicate recovery efforts. This results in an 
extremely important unanswered question: What is the largest asteroid that society can safely tolerate, if it hits in a sparsely populated area?

Immediate vs. Long-Term Effects: The immediate effects of an asteroid strike include shock waves that can knock down forests and buildings, thermal radiation that can set fire to the surrounding environment, and tsunami waves for impacts in the ocean. For the smaller impactors that are much more common, these immediate effects should be quite localized and of minimal concern if they occur in remote sparsely populated areas (e.g., Robertson \& Mathias, 2019a). Less dangerous, but potentially more costly long-term effects may result from debris deposited high in the atmosphere either from air burst of a comparatively small asteroid or ejecta from the ground impact of a larger one. (e.g. Robertson \& Mathias, 2019b) Fallout from the dust cloud will typically affect downwind locations over a much wider area than just local effects. For example, in the Tunguska explosion in Siberia in 1908, trees were knocked down over a $25 \mathrm{~km}$ radius, but lofted matter created noctilucent clouds (white nights) for a fortnight over entire Europe from Siberia to the Atlantic Ocean, and fallout created anomalous tree growth everywhere to the North of the impact as far as the Arctic Ocean (Kasatkina \& Shumilov 2007). The Tunguska explosion is estimated to have been caused by a comparatively small meteor less than $100 \mathrm{~m}$ in diameter and had negligible effect on the global climate and commercial crops since it hit in a remote part of Siberia. An extremely important unanswered question is, what is the largest meteor that society can safely tolerate allowing to impact in a sparsely populated area? The immediate effects have been well studied, particularly in modern years with hydrocode simulations, but the effects of the vapor, dust, and debris lofted into the atmosphere and falling out downwind or remaining aloft is only just beginning to be studied (Robertson \& Mathias, 2019b, Tabor et al., 2020).

Downstream effects. When a large asteroid impacts the earth, the blast wave and thermal wave will destroy natural (e.g., vegetation) and anthropogenic (e.g., concrete) ground cover and alter the biological, chemical, physical and hydrological properties of soils at the site of the impact (Robertson \& Mathias 2019a, Kletetschka et al 2017). The best analog to these changes to landcover and soils are wildfires, which cause rainwater to run off faster from the land surface and more quickly fill natural (streams, lake) and man-made (reservoirs) surface water bodies (Hallema et al., 2017, 2018; Murphy et al., 2018; Sankey et al., 2017; Smith et al., 2011; Weidner and Todd, 2011). Human reliance on surface water for drinking varies geographically based on population density, local and regional ground vs. surface water supplies, and infrastructure for water storage, delivery and treatment (see Fig. 1).

Downwind Effects: Although no recent documented asteroid impacts or air bursts have affected agricultural food crops, volcanic eruptions could serve as analogs. Volcanic eruptions release substantial amounts of ash into the atmosphere. For example, geologic evidence indicates that ash from previous super-volcanic eruptions has traveled over $6000 \mathrm{~km}$ and ejected enough particulates to cover North America in $100 \mathrm{~cm}$ of dust (Baines \& Sparks 2005; Jones et al, 2007). The Yellowstone hotspot has erupted approximately 2100, 1300, and 640 thousand years ago, 
depositing approximately $2450 \mathrm{~km}^{3}, 280 \mathrm{~km}^{3}$, and $1000 \mathrm{~km}^{3}$ of material over half of the Continental US (Mastin et al 2014).

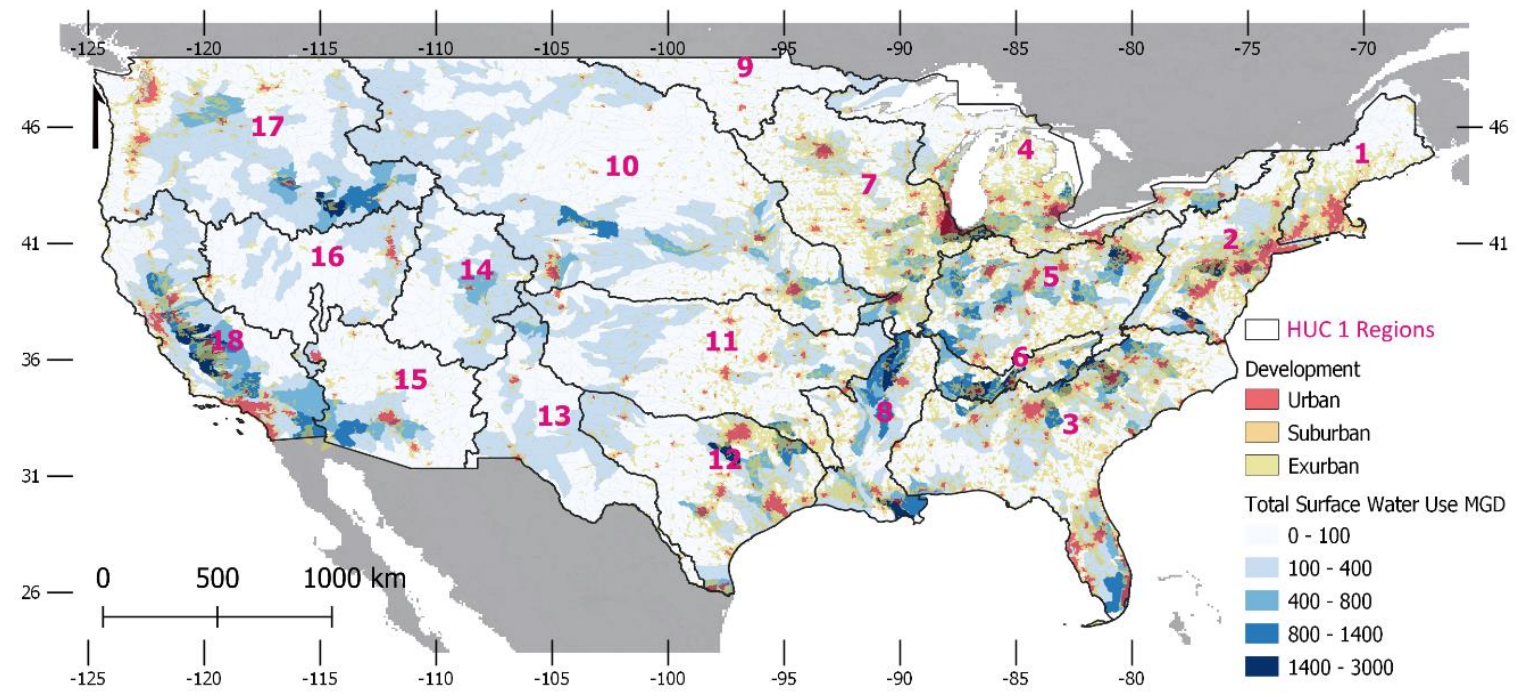

Figure 1: Watershed boundaries, human development, and surface water use across the US. Note that the surface water use in any one locality varies by the human population, agricultural production, relative availability of local and regional surface-vs. groundwater supplies, and infrastructure for water storage, delivery, and treatment. Also note that surface water supplies at any one locality originate in distal upstream areas of the watershed. [Data sources: HUC watersheds boundaries from Watershed Boundary Dataset (USDA 2019, Accessed September 1, 2009.), developed land data from the 2016 NLCD (USGS 2019), surface water use data from Forests 2 Facets (USDA 2019).]

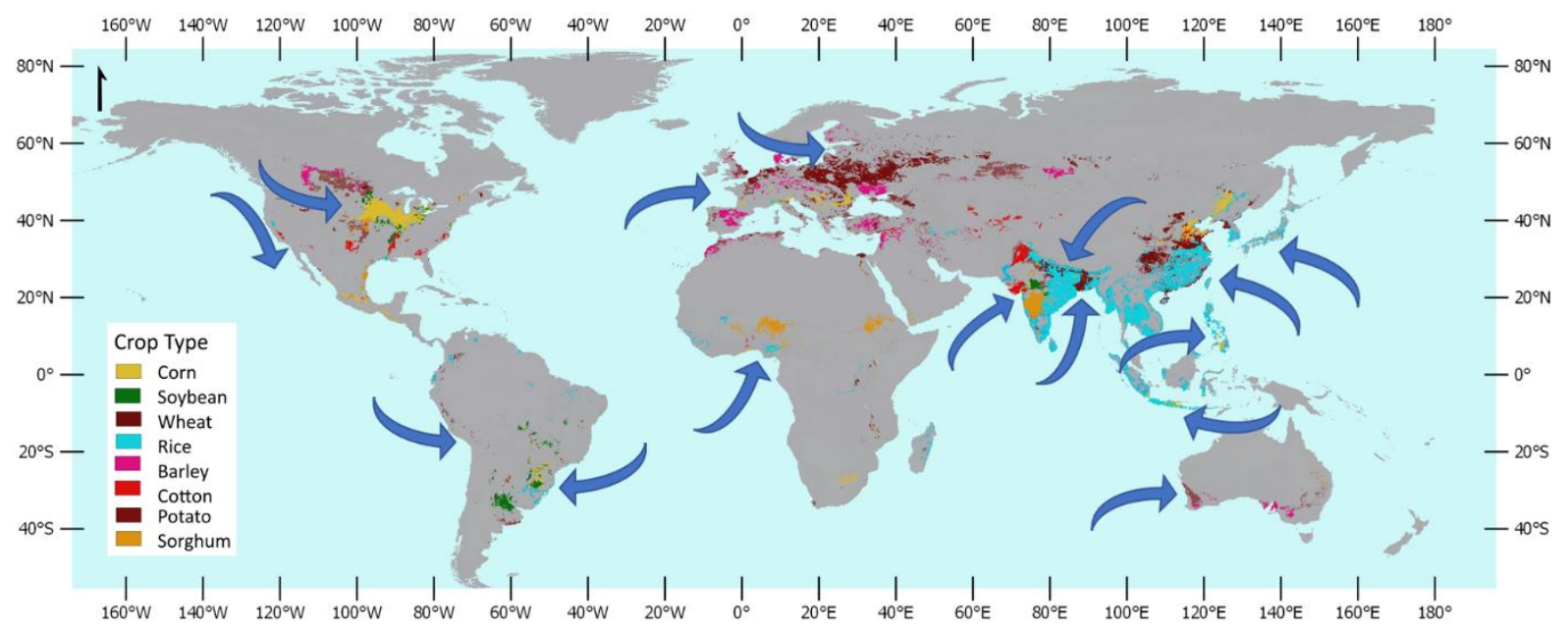

Figure 2: Major global agricultural areas and the dominant crop grown in each location. Blue arrows indicate prevailing winds during emergence to flowering (pollination) season when crops are most affected by windborne particles. [Data sources: Crop data from Sacks et al. 2010. Wind data from IRI 2020, accessed 5/20/2020.] 
The volcanic eruptions show how material lofted into the stratosphere can circumnavigate the globe and have significant climate impacts for month and years (Baines \& Sparks, 2005; Oppenheimer, 2003). As with volcanic eruptions, coarser particles will fall or rain out over downwind areas over the days after the meteorite impact. These more regional deposits may have a significant effect on air and ground transportation and the ecosystem, such as the yield of crops, and habitability of rivers and lakes, which lasts for months to even years.

The thickness of dust deposits also determines plant recovery: with 5-25 mm of deposition, most plants recover in one season although yields may be reduced; with $25-150 \mathrm{~mm}$, a large portion of plant cover is eliminated for more than one year, and soil recovery takes 5-10 years. Effects of dust on crop production vary by seasonality; crops are most sensitive to dust and heat from emergence to flowering (pollination) (see Fig. 2). Additionally, high value crops such as fruit and vegetables are particularly sensitive to dust (Neild et al. 1998). These longer-term effects have not yet been studied and quantified in any detail and are important to determine the economic and societal effects, particularly in rural areas.

Current State of Modeling and the Gaps in Knowledge: A few teams have coupled the output of hydrocode simulations of the impact to global climate models and used this to estimate the effects of the Chicxulub impact in the Yucatan peninsula which killed the dinosaurs (Pierazzo \& Melosh, 1999). The critical size of the impact to trigger non-local effects is poorly understood, and efforts are currently ramping up to expand these models to smaller impacts.

Recent hydrocode simulations have examined the amount of lofted materials for generic impacts in the 250 to $2500 \mathrm{~m}$ diameter range (Robertson \& Mathias, 2019b; see Fig. 3). This work finds that the non-local impacts grow from negligible to potentially devastating on a global scale. Even on the low end, a 250-m asteroid may have similar effects as the Mt. Pinatubo eruption in 1991, which caused almost 1 billion USD damage to crops and infrastructure in the Philippines. However, the global temperature drop of $0.5^{\circ} \mathrm{C}$ for the following two years had negligible effect on worldwide crop production.

Current hydrocode simulations typically only treat materials with a single equation of state, and do not explicitly differentiate in each cell, the fractions of solid, liquid, vapor, and certainly not the particle size distributions of dust and droplets (Robertson \& Mathias, 2019b). However, variations in the nature of the materials are important as one moves radially outward from an impact (Robertson \& Mathias, 2019b). An asteroid impact will vaporize the asteroid and the immediate area below the impact. A little farther out, the ground will be melted, much of which will be ejected into the atmosphere. Farther out still, the ground will be pulverized with large amounts of dust and debris also being ejected into the atmosphere. Current simulations do not quantify the ratios and particle distributions, nor their evolution as materials melt and vaporize in the fireball from the impact, and their condensation and solidification as the fireball cools. Modelling these distributions is an important step in understanding how long each component with remain lofted, and how quickly it will fall or rain out depending on the local weather 
conditions. These models can be constrained by data from impact craters on Earth, especially the well-studied Barringer Meteor Crater in Arizona (e.g. Roddy \& Shoemaker, 1995).

In the next decade, improvements should be made to the outputs of the hydrocode models so they can directly predict the phase and particle size distribution of the ejecta from the impact. This output can then be used as input into models for the transport, weather, and evolution of the ejecta, to determine what falls where downwind of the impact. This in turn provides the input for the effects on the crops, watersheds, and ecosystems. Finally, the costs associated with lost or reduced crops and mitigation of damage to the water system and ecosystems, can be analyzed.
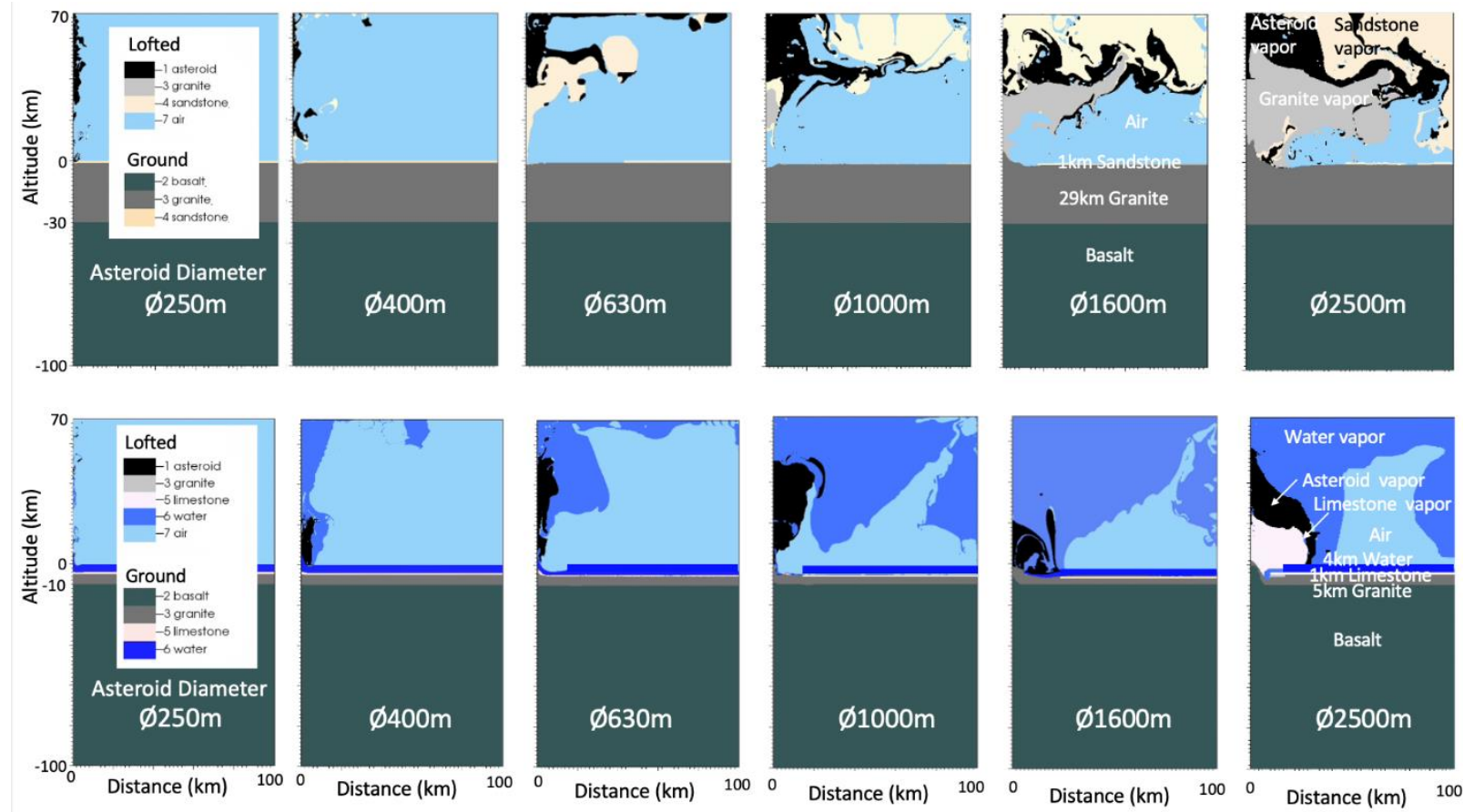

Figure 3: Example of current hydrocode impact simulations for a range of asteroid sizes into a nominal continental and oceanic surface, and the amounts of lofted materials (Robertson \& Mathias, 2019a). In these simulations, lofted materials are homogenized but in future work the distributions of particle sizes and ratios of solid to liquid to vapor will need to be determined to understand how the materials fall out downwind and subsequently affect the environment.

Conclusions/Recommendations: Being prepared for any potential hazard is key to minimizing the effects on life, property, and the economy. Our actions, if not appropriate and informed, can be needlessly counterproductive for long-term mitigation. Over the next decade, further research is needed to identify and characterize downwind and downstream effects that result from an asteroid impact. These results can then be used to provide actionable recommendations for mitigation of these effects. For example, some mitigation efforts could be as simple as evacuating the immediately affected population to a different watershed. Particularly in the western US, individual communities have action plans for managing watersheds and infrastructure to reduce the risk and effects of wildfires on their municipal drinking water supply. 
These examples could provide effective protocols to reduce delayed effects on water supply from impacts. Especially for downwind effects, knowing the seasonal sensitivity of crops to different thicknesses of dust with differing compositions is important. The main finding of this white paper is that we need to know when these delayed effects need to be considered in civil defense planning and when they can be ignored.

To accomplish these goals, the following would be beneficial: (1) Continue research to identify current models for downstream and downwind events and to determine how to interface the input parameters into these models with the output from the impact and air burst models. This includes the determination of debris, dust and ash production, composition, and grain-size profiles. (2) Identify gaps that prevent the seamless interface between a multitude of models that include, but are not limited to, impact hydrocode, general circulation models, streamflow models, ash distribution models, models of transportation networks, and crop production. (3) Identify gaps in modeling capabilities for potential delayed effects that may be displaced in both geography and time from the impact origin. (4) Use more frequently occurring natural disasters to validate the models. This information could also play a critical role in responding to more common disasters (such as severe drought, flooding, wildfires, political conflict, hurricanes, earthquakes, volcanic eruptions, and tsunamis).

To enable a reasonable decision on whether to mitigate an impactor in space or to merely evacuate the impact zone, having a good understanding of the costs associated with both is important. The cost to launch a mission to intercept an asteroid is well known, but the long-term costs of an impact may be seriously underestimated if longer term effects are not considered.

\section{References}

Baines, P.G. and Sparks, R.S.J., 2005, Dynamics of giant volcanic ash clouds from supervolcanic eruptions. Geophysical Research Letters, 32(24), CiteID L24808.

Collins, G. S., Melosh, H. J., and Marcus, R. A., 2005, Earth Impact Effects Program: A Webbased computer program for calculating the regional environmental consequences of a meteoroid impact on Earth, Meteoritics \& Planetary Science 40(6) 817-840.

Hallema, D.W., Sun, G., Caldwell, P.V., Norman, S.P., Cohen, E.C., Liu, Y., Bladon, K.D. and McNulty, S.G., 2018, Burned forests impact water supplies. Nature Communications, 9(1), 1.

Hallema, D.W., Sun, G., Caldwell, P.V., Norman, S.P., Cohen, E.C., Liu, Y., Ward, E.J. and McNulty, S.G., 2017, Assessment of wildland fire impacts on watershed annual water yield: Analytical framework and case studies in the United States. Ecohydrology, 10(2), p.e1794.

Hills, J. G. and Goda, M. P., 1993, The Fragmentation of Small Asteroids in the Atmosphere, Astronomical Journal, 105, 1114.

Jones, M.T., Sparks, R.S.J. and Valdes, P.J., 2007, The climatic impact of supervolcanic ash blankets. Climate Dynamics, 29(6), pp.553-564. DOI: 10.1007/s00382-007-0248-7

Kasatkina, E. and Shumilov, O., 2007, One more puzzle of the Tunguska catastrophe? JETP Letters 85, 216-219. 
Mastin, L.G., Van Eaton, A.R., and Lowenstern, J.B., 2014, Modeling ash fall distribution from a Yellowstone supereruption, Geochemistry Geophysics Geosystems, 15, 3459-3475.

Murphy, B.P., Yocom, L.L. and Belmont, P., 2018, Beyond the 1984 perspective: Narrow focus on modern wildfire trends underestimates future risks to water security. Earth's Future, 6(11), 1492-1497.

Neild, J., O'Flaherty, P., Hedley, P., Underwood, R., Johnston, D., Christenson, B., Brown, P. 1998, "Impact of a Volcanic Eruption on Agriculture and Forestry in New Zealand," MAF Policy Technical Paper 99/2, ISSN: 1171-4662, ISBN: 0-478-07989-3

Oppenheimer, C., 2003, Climatic, environmental and human consequences of the largest known historic eruption: Tambora volcano (Indonesia) 1815. Progress in Physical Geography, 27(2), 230-259.

Pierazzo, E. and Melosh, J., 1999, Hydrocode modeling of Chicxulub as an oblique impact event, Earth and Planetary Science Letters, 165(2), 163-176.

Robertson, D. and Mathias, D., 2019a, Hydrocode simulations of asteroid airbursts and constraints for Tunguska, Icarus 327, 36-47.

Robertson, D. and Mathias, D., 2019b, Atmospheric injections from kilometer scale asteroids, IAA Planetary Defense Conference, May 2019, Washington D.C.

Roddy, D. J. and Shoemaker, E. M., 1995, Meteor Crater (Barringer Meteorite Crater), Arizona: Summary of impact conditions, Meteoritics, 30(5), 567.

Rumpf, C. M., Lewis, H. G., and Atkinson, P.A., 2017, Asteroid impact effects and their immediate hazards for human populations, Geophysical Research Letters, 44(8), 3433.

Sacks, W.J., D. Deryng, J.A. Foley, and N. Ramankutty, 2010, Crop planting dates: an analysis of global patterns. Global Ecology and Biogeography 19, 607-620.

Sankey, J.B., Kreitler, J., Hawbaker, T.J., McVay, J.L., Miller, M.E., Mueller, E.R., Vaillant, N.M., Lowe, S.E. and Sankey, T.T., 2017, Climate, wildfire, and erosion ensemble foretells more sediment in western USA watersheds. Geophysical Research Letters, 44(17), 8884.

Smith, H. G., G. J. Sheridan, P. N. Lane, P. Nyman, and S. Haydon, 2011, Wildfire effects on water quality in forest catchments: A review with implications for water supply, $J$. Hydrol., 396, 170- 192.,

Tabor, C., Bardeen, C., Otto-Bliesner, B., Garcia, R., and Toon, O., 2020, Causes and climatic consequences of the impact winter at the Cretaceous-Paleogene boundary. Geophysical Research Letters 47 e60121.

U.S. Geological Survey, 2019. NLCD 2016 Impervious Surface Conterminous United States. Sioux Falls, SD.

Weidner, E., and A. Todd (2011), From the forest to the faucet: Drinking water and forests in the US. Methods paper, ecosystem services and markets program area, State and Private Forestry. USDA Forest Service. 